\title{
Noa Nagane
}

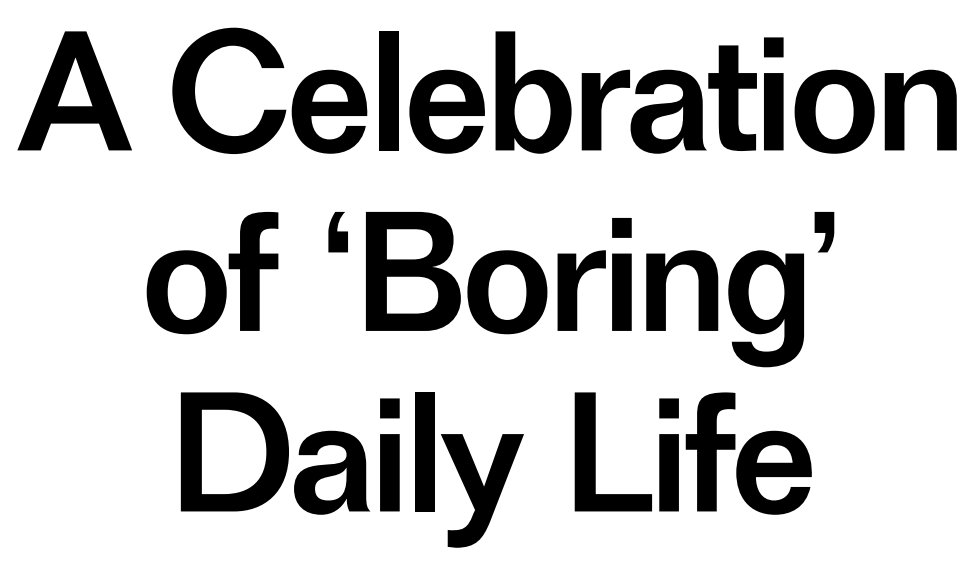

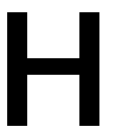

ow should I design 'Architecture'? This has been the most important question for me since I started studying architecture. I was born and grew up in a new residential area next to Tokyo. My hometown was filled with typical industrialised housing. There is no 'architecture' designed by 'architects' nor are there beautiful traditional houses. As I started to study architecture at university, I found out that houses like mine were 'boring' buildings produced by a mass consumerist society and are not considered 'architecture'. I studied many architectural masterpieces and was fascinated by them, but I still had many questions. 'Buildings' like my house might be considered 'boring', of course; however, I, my family and many people live a precious life in them. Are our daily lives in these 'boring' buildings boring? Is there no fascination in our lives?
Fig. 1 is a photo of the city after the 2011 Tohoku earthquake and tsunami. At that time, I was a junior high school student. I was in my classroom and checking my result of term-end exams. Suddenly, the ground moved violently. (Although it was a small tremor compared to Tohoku.) That night I had to stay at school because all public transportation was stopped. The next morning, I came back to my home and watched the news on the television. It was then that I realised what a disaster this was. This experience taught me that daily life can be destroyed suddenly, easily and entirely.

That could happen anywhere, all over the world, not just in Japan. Even now some countries are in conflict and Europe is also exposed to the dangers of terrorism. Daily life can easily disappear and it cannot easily be replaced. We don't know what we have until it's gone. 
If you feel that your daily life is boring now, you have overlooked all the fascinating things in your everyday life. I believe that one of the most important roles of architecture is to help people find fascination in this 'boring' daily life and to brighten it. Such architecture would help everyone to accept not only the happiness but also the sadness in every life and to find hope in it. I want to celebrate 'boring' daily life by such life-affirming architecture.

To find a way to design life-affirming architecture, I would like to mention three concepts: 'Quality Without Name', 'Livedin Space' and 'Little Spaces'.

'Quality Without Name' is one of the topics of The Timeless Way of Building ${ }^{1}$ written by Christopher Alexander:
"There is a central quality which is the root criterion of life and spirit in a man, a town, a building, or a wildness. This quality is objective and precise, but it cannot be named." (p.19)

In order to reach the 'Quality Without Name', he analysed daily life and wrote A Pattern Language. ${ }^{2}$

However, 'A Pattern Language' as a method is not perfect. The Lived-In House: Experience and Symbol $^{3}$ was written by Koji Taki, a Japanese art critic. This book is called Archeology of Architecture. Taki considered the "house" not as "a container" for living in, but as "text" which human time and spaces are weaved into. "Living-in" experience is an interaction between the environment and the subject. Taki did not only define this interaction, but he also

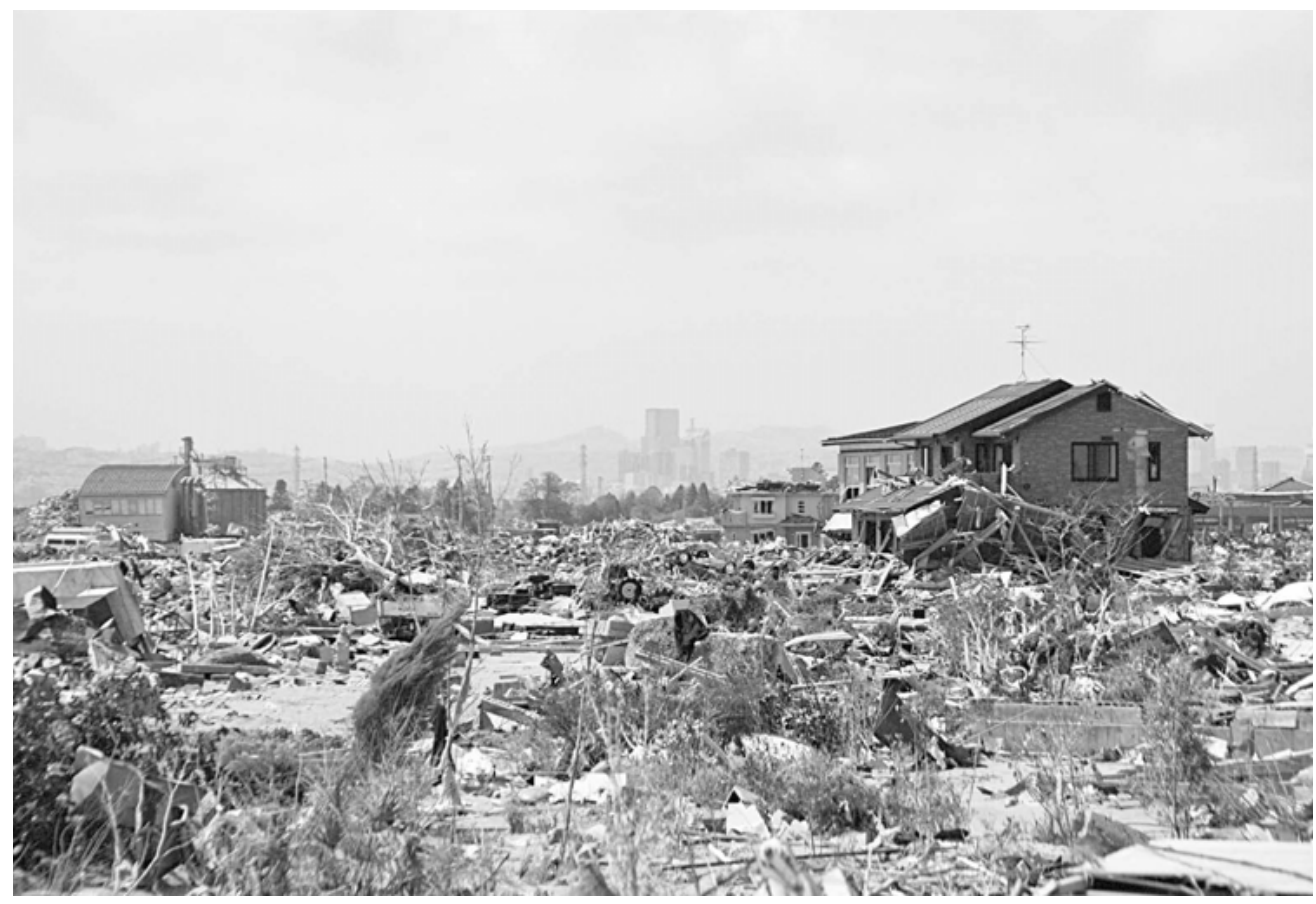

Fig. 1 Tohoku after earthquake and tsunami. 


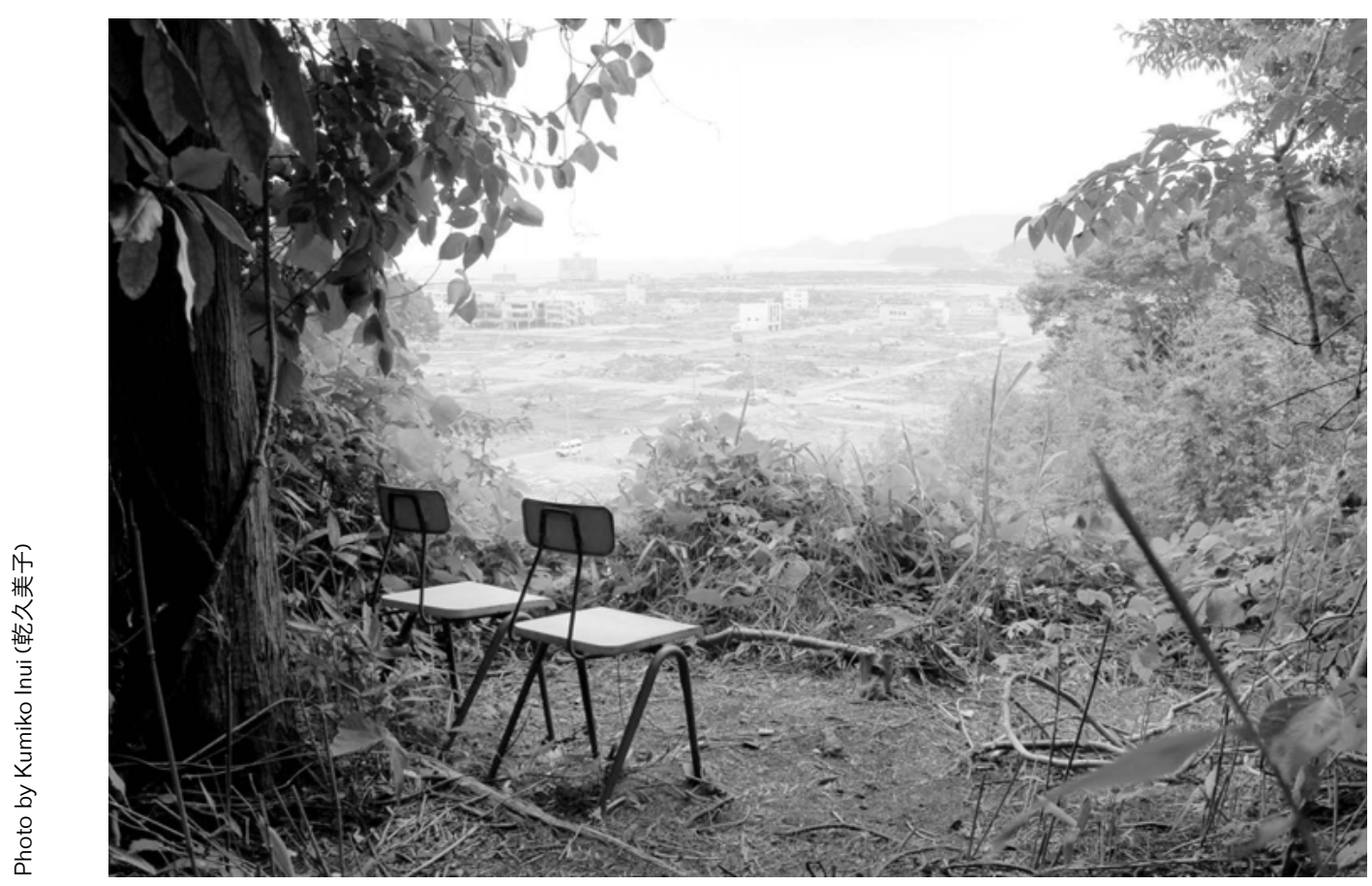

Fig. 2 Kumiko Inui, Tokyo University of the Arts Inui Lab. (2014). Chiisana Fuukei karano ManabiSamazama na Sabisu no Hyoujou [little spaces]. TOTO Shuppan. p. 2-3.

criticised urban theories in the 1960s, such as The Image of City by Lynch and A City Is Not a Tree by Alexander.

"It can be said that these new urban theories which replaced symbolic anthropological theories use scientific language as a tool and therefore remove language which can describe the relationship with something archaic." (p. 228, present author's translation)

He said that, "In order to catch the city's murmur - which we cannot understandand melancholy," a "poetics" is needed. He tried to capture the quality by "poetics."

There were many trials to reach 'the quality' of 'lived-in space'. The most important one for me is, Little Spaces ${ }^{4}$ written by Kumiko Inui, a Japanese architect and professor of Yokohama Graduate School of Architecture.
She also tried to achieve 'lived-in space' and analysed 'little spaces'. 'Little spaces' are spaces which ordinary people have discovered, freely and patiently, and worked at to put to full use. 'Little spaces' are full of richness and creativity of human awareness $v i s-\hat{a}$-vis spaces and places. She also mentioned A Pattern Language:

"In A Pattern Language, it might be said that he ignored 'something reminds people of quality', because he focused on extracting [a] universal diagram from real phenomena." (p. 9, present author's translation)

The photo (Fig. 2) and texts by Inui show what richness 'little spaces' have to offer.

"That was the moment I went to see the disaster area of the 2011 Tohoku earthquake and tsunami. In order to observe the entire city 

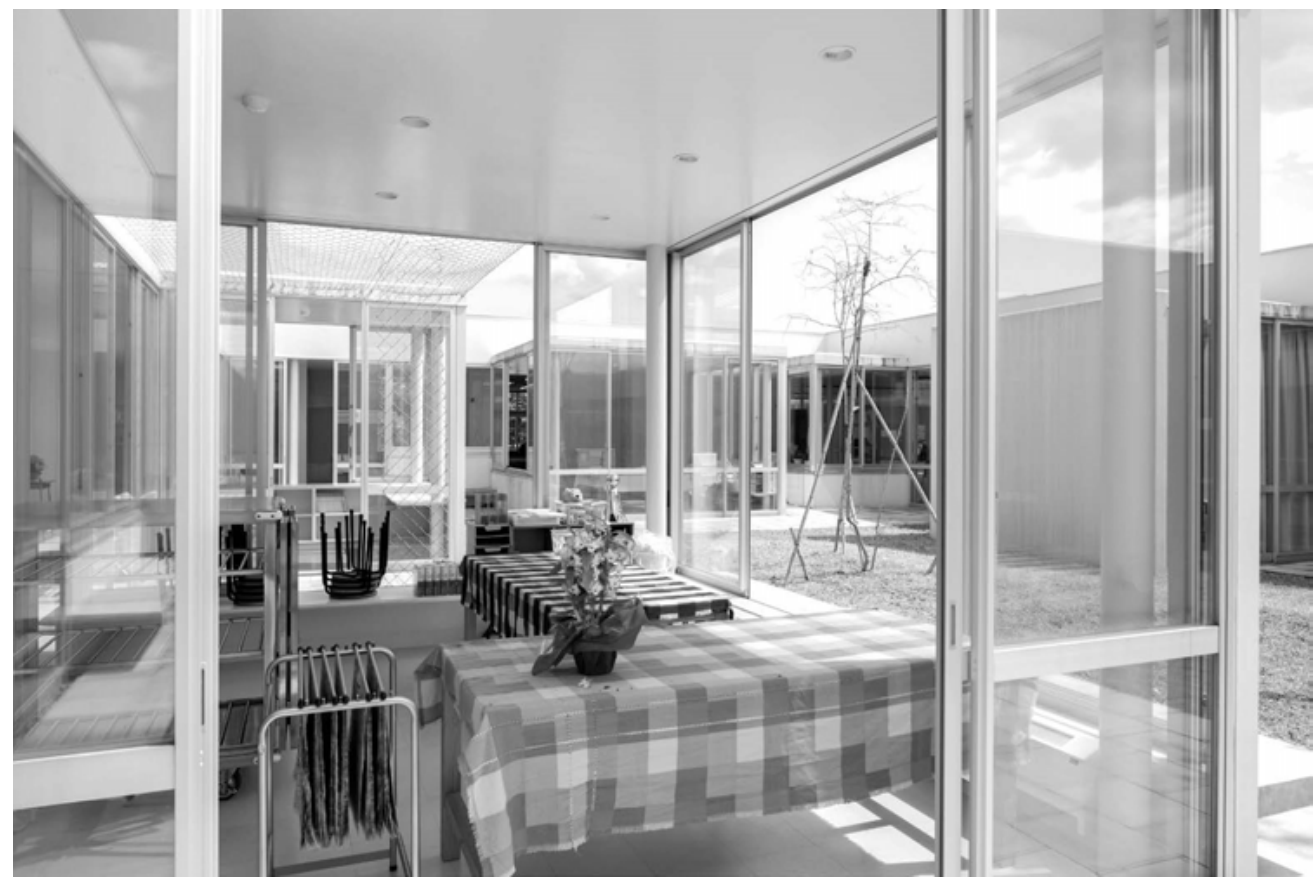

Fig. 3 Kumiko Inui (2019). Inui Architects. LIXIL Publishing. p. 100-101.

where there was still a lot of rubble left, I visited ajunior high school on the top of a small hill and finally found the place where we can see the whole city silently. The hurtful sight was framed by the trees softly and there were two chairs on the little flat space. Someone living in the temporary houses in the school yard often came here and thought about his/her former life. In order to help this moment, someone found this place, and someone else brought these chairs from the school.... I was moved by the kindness of this small space who would embrace people warmly." (p. 2, present author's translation)

She collected tens of thousands of pictures of those 'little spaces' to figure out their structure. She avoided making diagrams and abstracting these spaces. She made groups and named them with short notes. Then, by arranging many pictures, in contrast to Taki's "poetics," she tried to show their "quality."
As regards the representation of her work in photography, her picture of a junior high school reconstructed after the earthquake in Tohoku (Fig. 3) shows her attitude towards architecture. A teddy bear, Winnie the Pooh, is just visible at the back of the room. Usually architects remove these types of unwanted or even 'ugly' objects when they take photos of their work, but Inui left it there intentionally, because this is what daily life is and that bear shows how this architecture is actually used. ${ }^{5}$

To try and capture this quality myself, I analysed the relationship between architecture and bicycle parking. When we park a bicycle, we read the environment, find a space which doesn't bother others, then we park. So, the act of parking a bicycle is an interaction between people and architecture. I started this 
specific and concrete topic because 'how to catch the quality' and 'how to design lived-in space' are too magnificent themes to connect with design methods. I took around 1000 photos of bicycles and analysed them, as Inui did, in order to find the quality which makes people act. In classifying these 1000 photos, I felt like a deeplearning program that was being trained.

In fact, deep learning technology is approaching very similar object recognition as the Chihuahua or Muffin Problem. Many engineers try to increase the accuracy of recognition, but I would like to focus on 'mistakes'. Sometimes these programs classify different objects as the same by mistake. For example, they might classify a chihuahua as a muffin. It is a mistake.
We would not mistake a chihuahua as a muffin in reality. But they are very similar. Thus, this mistake makes us find their similarities. So it might be said that deep learning technology can help us to realise similarities which we usually overlook.

Going back to Inui's research, as I previously mentioned, she collected a huge number of photographs and classified them by defining similarities in 'little spaces'. Finding similarities is connected to finding the hidden 'quality'. 'The quality' in 'lived-in space' which we find will be the clues to design a new quality and a new lived-in space. By embedding these qualities, we could design lifeaffirming architecture which celebrates 'boring' daily life.

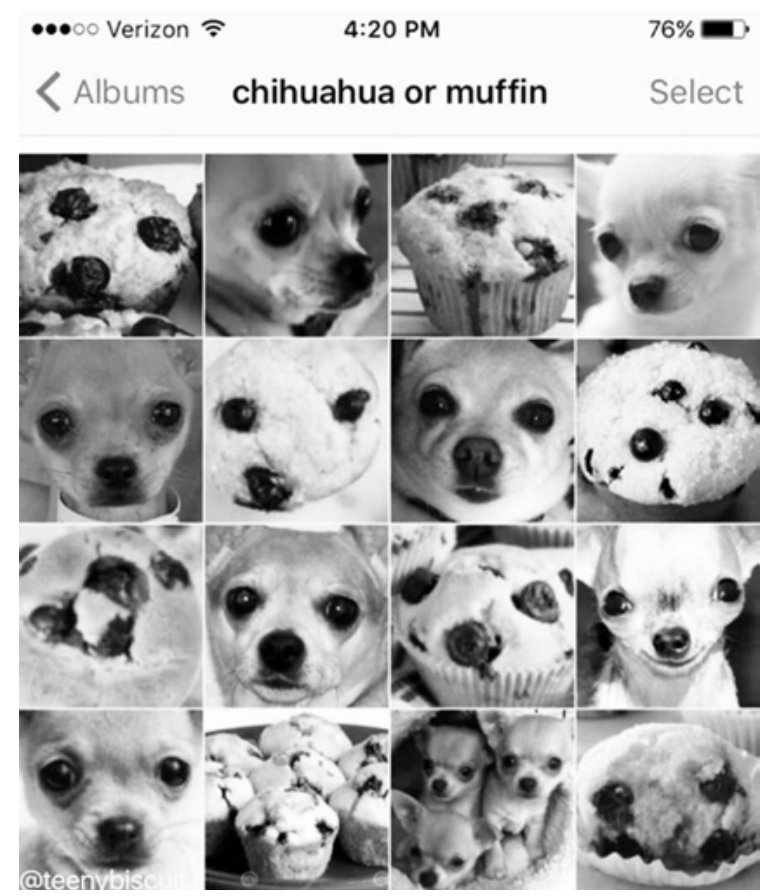

Fig. 4 Chihuahua or muffin? 
Careful and patient observation is needed to find the quality of fascination in 'boring' daily life. I believe that the combination of human intuition, our senses and machine intelligence will pave the way to celebrate 'boring' daily life through architecture.

1 Christopher Alexander. (1979). The Timeless Way of Building. Oxford University Press.

2 Christopher Alexander. (1977). A Pattern Language. Oxford University Press.

3 Koji Taki. (1984). Ikirareta Ie - Keiken to Shocho [The Lived-In House - Experience and Symbol]. Seido Sha.

4 Kumiko Inui, Tokyo University of the Arts Inui Lab. (2014). Chiisana Fuukei karano ManabiSamazama na Sabisu no Hyoujou [little spaces]. TOTO Shuppan.

5 Winnie the Pooh in this photo was discussed in detail by Takahiro Omura in the context of 'punctum' and 'studium', the concepts of Roland Barthes. (Takahiro Omura. (2019). Naze Soko ni Puusan ga Irunoka - 『Inui Architects-Inui Kumiko Kenchiku Sekkei Zimusho no Shigoto』shohyo [Why is there Winnie the Pooh? - Book Review of 'Inui Architects'].

http://10plus1.jp/monthly/2019/08/issue-03.php) 